\title{
Contemporary International/World Novels' Transmissibility from Partial Connections to Hermeneutics of Situation (With References to Glissant, Volpi, Murakami, and Rushdie)
}

\section{JEAN BESSIÈRE}

\begin{abstract}
Due to its formal and semantic flexibility, the novel is often viewed as exemplarily associated with globalization. Most interpretations of this view lead to a paradox - presentations that the genre of the novel offers can be specific, and yet, widely circulated - and refer it to transnationalism, to the worlding of many cultural identities, or to some kind of literary space. These interpretations leave open the questioning of the cultural denotations or literary features that empower novels to be widely circulated and universalized. This article identifies and analyzes this explicit questioning in Glissant's Toutmonde, Murakami's Kafka on the Shore, Rushdie's The Moor's Last Sigh, and Volpi's In Search of Klingsor, and suggests a quadruple answer.

1. Contemporary novels, that are read as world novels, reflect the paradox that qualifies their world circulation: they designate and deconstruct the signs of the universal by offering totalizing and detotalizing perspective and by questioning their universalization potential.
\end{abstract}

2. This formal and semantic paradox is presented by means of "partial connections", i.e. objective or imagined references to distant or non-identical cultural references that can be viewed as partially overlapping. Partial connections impose a metonymic view of all chains of cultural mentions, and, between the latter, delineate special kinds of union - differences coexist and unite, and their discontinuities invite to view them as equally real. Partial connections found world novels' rhetoric and transmissibility.

3. Due to these partial connections, some kind of specific hermeneutics is developed or implied - hermeneutics of situation. No overall interpretation of their own universalizability is offered by world novels - they generate symptomatic readings.

4. Remarkably, these literary and cultural montages apply to canonical kinds of novel - investigation novel (In Search of Klingsor), historical novel (The Moor's Last Sigh), Bildungsroman (Tout-monde, Kafka on the Shore), that are most often recognized as universal because of their canonicity and the readability they show. On the one hand, these montages alter the canonicity and readability of these kinds of novels, on the other, they trigger their wide circulation because they negate any rule of reading and any overall 
interpretation, and however suggest some kind of universal hermeneutics - the use of partial connections is of utmost importance.

Keywords: novel; world novel; transmissibility; universalization; totalization/ detotalization; partial connections; Édouard Glissant; Jorge Volpi; Haruki Murakami; Salman Rushdie

It should appear very common and unoriginal to address issues about contemporary novel's international trends and their association with globalization and the world - all the more common and unoriginal because this kind of approach often offers a wide archeology of this contemporary international/ world novel, and conflates with rewriting many traditions in the study of the novel. Let us decide not to use these wide views and to emphasize two obvious facts: many international novels in many languages are widely circulated; any of them is a minor token of this rich production and circulation, and a minor cultural symbol within our broad world. These short remarks result in a paradox: the most widely written, translated and recognized literary genre, the best exemplification of literary globalization and of our wide multinational and multicultural world, should be identified and read as "detotalizing" any designation of this world. This paradox points to one more paradox: this "detotalization" does not prevent the many international/world novels from being widely circulated and designating our broad world and its universalities. Both paradoxes lead to a few questions: how do contemporary international/ world novels, even though they remain minor cultural symbols, construct representations that enable cosmopolitan readings and the transmissibility the latter presuppose, and exemplify global differences - differences that fit universalities? ${ }^{1}$ How can these novels be ubiquitous or figure ubiquity, while they are obviously specific and singular by their style and cultural references? How can they offer images or imaginaries of the universal or of universalities

1 Our references are to four novels: Glissant's Tout-monde, an international novel that presents world perspectives, with no translation in any language; Volpi's In Search of Klingsor, an investigation novel with world perspectives and widely translated and circulated; Haruki Murakami's Kafka on the Shore, a Japanese bildungsroman with restricted world perspectives, and widely translated and circulated; Rushdie's The Moor Last Sigh, a historical novel, with national and international cultural perspectives, and widely translated and circulated. The diverse kinds of novels and the various statuses for what regards international/world themes and world literature, that these novels exemplify, should enable to suggest a poetics of contemporary international/world novels. 
BESSIÈRE

even though they do not designate the earth as that whole that contains all the possible evocations of many places and times, and do not necessarily suggest references to the people and literatures of the world? Critics have offered many responses to these questions. One specific answer should be to define the formal, semantic and symbolic characters that enable contemporary international/world novels to exemplify the paradox of their ubiquity.

\section{Of the International/World Novel and Some of its Paradoxes - about Glissant's Title, “Tout-monde” [All-World]}

Glissant's title of his international and world novel, Tout-monde, emblematizes the contradictions that trigger these questions: it means "all the people" in creole, and any world and/or the whole world in French. None of these meanings is to be rejected even though Glissant's novel neither evokes all the people, nor the whole world nor any world as exampling the world - all Tout-monde's worlds are specific. In addition, Glissant's title points to the reflexive paradox that defines his novel: the latter fails to provide adequate and congruent images of the whole world, any world and "tout le monde"; however, this failure enables us to delineate what we call "partial connections" that designate the novel's transmissibility, universalizability and consequently universalities. Most of contemporary international/world novels exemplify the alliance of these perspectives: totalization, detotalization, partial connections and universalities. We should add one more expression to characterize these novels' transmissibility: one of the meanings of Glissant's title ("tout le monde"/“all the people") points to these novels' general or universal audience. This notion is paradoxical. No audience can be qualified as universal because it is always specific, with particular codes, expectations, etc. However, it can receive this qualification because readers recognize and repeat while reading a constant specificity of international/world novels' characters: the latter's experiences and interpretations of their worlds make them self-transcendent.

This reading of Glissant's title as emblematizing the tensions of the contemporary international/world novel demonstrates that the latter neither fits a global definition of the novel, nor authorizes the recognition of general or universal cultural paradigms. However, due to these tensions, this kind of novel can be viewed as rich in broad scopes - with no pointing to general humanity, and no equal identifications of their forms, themes and contents. The suggestions of broad scopes do not erase any formal, semantic or cultural disjuncture. The alliance of broad scopes and disjuncture makes of these novels responses to the contemporary interplay of the global and differences - one 
more way to view the duality of totality and detotalization. It highlights the view of our world that can be read in Glissant's title: because this world is the location of literary and cultural multiplicities, it appears indefinite and consequently the figuration of the universal. Or in other words: we can figure our worlds and this world, works and literature, people and individuals as assembled with no reference to a priori categories. The modalities of the designations of universalities are many and do not cancel heterogeneities. They exemplify these remarks by William James: there are "special kinds of union which the universe enfolds. We found many of these to coexist with kinds of separation equally real." (James 1921: 165)

These paradoxical unions and this equally paradoxical enfolding exclude any "absolute distinction" - the recognition of any difference as absolute and any overall view or "commanding viewpoint" (Kapferer 2011: 104). The representation of paradoxical unions and real separations presuppose to delineate specific connections that are partial. "Partial connection" is a notion widely used by contemporary anthropologists (Strathern 2004). It refers to the many connections which ally cultures with no suggestion of overall links and that are consequently always incomplete. Cultural situations and their details partially overlap or share similarities, especially when they are time or space distant. The notion refers also to comparisons (in anthropology, in sociology and in literature), which point to the bifurcations and relations - manifest or reconstructed - of differences. In literary works, partial connections between worlds' agents, characteristics, etc. can be delineated in order to represent and to account for the duality of the "paradoxical unions" and the "enfolding world". Remarkably, these partial connections are necessarily bidirectional: the reading from the difference $A$ to the difference $B$ can be reversed, and the reversion can apply to temporal differences.

Glissant's title invites us to view his novel as a series of partial connections: it refers to the whole world by the means of continuities that divide. It at once repeats the usual image we have of our world - broader than all the worlds that people recognize and consequently their container - and reverses it into the image of a world that appears as the extension of all these worlds, and of their people. This reversal makes us recognize the world's plasticity and completeness, and defines the transmissibility of the novel.

Remarkably, the same partial connections and the same reversal of the presentation of the world can be found in the classic kinds of novels that happen to be international/world novels - the detective and investigation novel, the Bildungsroman, the historical novel. In principle, these kinds of novels should show clear and unambiguous narrative teleology - the investigation 
BESSIÈRE

novel and the conclusion of the investigation, the Bildungsroman and the highly normative function of events and actions, the historical novel and the insertion of individuals in collective time-lines. These basic qualifications are not congruent with the presentation of paradoxical "unions" that "coexist with separations equally real". However, some international/world novels demonstrate that this teleology and its semantics can be reversed, and that classic kinds of novels do refer - specifically - to "tout-monde", the "enfolding world" and its "paradoxical unions" by using partial connections and designating this world as imminent (investigation novel), immanent (Bildungsroman) and commensurable with human subjects (historical novel). Glissant's divided and continuous images of the world and this reversing of narratives' teleology offer broad representations of our world with no meta-image, and enable us to respond to the duality of totality/detotalization, and to find the identifications of global differences, and the world transmissibility of the novels.

Some specific hermeneutics is associated with the paradoxical unions and "partial connections" that characterize these international/world novels. The latter can contain no broad hermeneutics; only what we call hermeneutics of situation is relevant. For what regards fictional characters, their practice of hermeneutics relies, on the one hand, on their observation of the disparity of the existents, and on their ability to delineate relations between them, and, on the other hand, on their power to seize their own act of existing through these relations. Engaged in this observation and this grasp, they transcend their own positions (within the fictional worlds) and can be viewed as co-existent with the "enfolding world" and able to figure universalities. Readers read this hermeneutics of situation, apply it to what they read, and eventually to their own situations and transcend their own positions. The self-transcendence that is attached to the act of reading defines the general/universal audience that is associated with these novels; it makes this act the mirror of the interplay of paradoxical unions, separate realities and the "enfolding universe".

\section{Partial Connections and the Completeness of our Disjunctive World - the Case of Glissant's Tout-monde [All-World]}

Glissant's Tout-monde [All-World] is a remarkable attempt to offer an image of the world and any people, and an equally remarkable exercise in turning its general point of view and dualities into "partial connections". A kind of kantism should be first read in the novel's transcultural-scapes, images of creolization and of the world, and exemplification of "littérature-monde" 
["literature-world"]. These representations imply an a priori, which makes it possible to view and to experience the diverse through the unity of the language and its vernacular versions and this world whose totality, which cannot be viewed but only imagined, is the condition to perceive heterogeneities. The same kind of kantism applies to the novel's characters' identifications. These characters' ethos amalgams the recognition of contingency and the desire to be identified by the signs of some kind of unity - the contemporary global order, which does not provide its own obvious image while it dismantles national orders (Bauman 2001), explains the double desire for globalism and unity. Glissant's characters move from Martinique to France, Europe and other countries, but always refer to the unity that defines specific places - Martinique, France, Europe -, and the alliance of contingency and globalism. The same kind of overall approach even though it cannot be qualified Kantian - applies to time and history. The novel invites us to apprehend the latter as a whole. The many "histories" that are evoked are all linked with colonization, World War II and postwar time. Due the amalgam which sequential historical events constitute, history and cultural references are conflated. While one can designate no law of history, the latter however seems self-totalizing. Tout-monde "can be seen to bespeak a desire for totalization in the medium of cultural experience" (Osborne 1995: ix).

Paradoxically, Tout-monde cannot be reduced to this Kantian frame, which any reading should disclose. To refer to the whole world and to view history as self-totalizing means to quote chains of singular places and many time segments. This continuous segmentation contradicts any explicit overall frame, because continuity and segmentation ally conjunctions and disjunctions, associations and dissociations, and the many stories which are narrated or referred to are not separable from the various scenes and dialogues. Any narration is united with others, either through the dialogues or the variations of the locations and times that are evoked. Remarkably, the many comments that emphasize references to the notion of relation are more comments on and many exemplifications of the notion than qualifications of the main narrative and its sub-narratives. Moreover, individuals' stable identities are literally defined as open: even though they remain stable, they show connections, which imply some kind of dissociation or, at the least, make these identities variable. (Glissant 1995: 185) The relations - associations and dissociations - are so many and trigger so many variations that they are obscure and consequently make identities obscure as well. Obscurity is the quality of relations that are partial connections - they cannot make their constitution manifest and leave 
BESSIÈRE

open the way they can be described, analyzed and their relevance assessed. The same remark applies to space: there is no longer any here and any there because any place is related to another place and both can be confused (Glissant 1995: 564). This confusion defines a spatial obscurity - to be aware of spatial confusions equates with becoming aware that this world, which should be viewed as a whole, seems unachieved or only designable by the chain of associations and dissociations. The same remark applies finally to time that is, by definition, a sequence of moments. Due to their sequence and proximity, moments are different and similar. This duality is exemplified by a character who died four times: he is not assimilated to a ghost, and figures the relations of these four distinct and different deaths and four moments. Space and time relations' obscurity authorizes us to freely compare and exchange their initial and final elements. Even though Tout-monde can be referred to the notion of totality, it substitutes for the codes that should unite its many places, times and people, connections that do not authorize us to characterize the novel's data according to complete parallelisms or similarities. These partial connections have not been theorized by Glissant and contradict the implicit kantism of his "poetics of relations" and its antecedent, Deleuze's analysis of multiplicity in Difference and Repetition. In Tout-monde, due to partial connections, differences remain differences even though they are global: characters', places' and times' singularities activate comparisons, similarities through a plurality of contexts, and are never designated by abstractions or assimilated to types - should it be a rhizome type.

These partial connections that are delineated have their origins in familiar identities, places and moments that appear dual: they show specific characteristics and more general ones because their occurrences that seem familiar make them metonymic. In other words, on the one hand, we certainly know things rationally and represent our world consequently; on the other hand, this knowledge and this representation are metonymic, and metonymy originates from the familiar. Due to the metonymic chains of the many partial connections, the "tout-monde", which Glissant describes, makes Martinique's daily life the basis for interpreting this world and viewing the former as including any broader scope and designating our whole world and Martinique as mutually metonymic. The word "mélange" [mixture] is often used in Toutmonde - anything can be a "mélange", and the "mélange" is a kind of invariant, according to Glissant (Glissant 1995: 560-565). To identify invariants presupposes to conceive of our familiar (local) world according to mutual metonymies: the novel's characters discuss, refer to their own experiences, and broaden the views they have of themselves - they are made parts of the world 
by the partial connections, and see this world and any of its agents and objects parts of themselves.

In Tout-monde, the whole is not incommensurate to any place because partial connections are delineated according to two reverse directions - from the local to broader spaces and from the latter to the former. The partial connections and their metonymies define Martinique as the interpretant of the world, assimilate the latter to an equal interpretant, and make any reference to the periphery and center duality irrelevant. Any identity should be consequently viewed as a universality, and the many identities as global differences because the world, the context of contexts, can only be the amalgam of the latter. The partial connections prevent us from identifying this world with a plane of immanence. (The latter is actually a principle of unification that should justify the many comments about relations - the discussions about food in the novel confirm this remark - and eventually the kantian and "rhizomatic" approaches to the novel.) Should we read some kind of unity in Tout-monde, it should be qualified analogically. All the stories that are narrated are homonymous because they are sequential and about the world and worlds, and, due to this sequentiality, their fictions and truths are analogical - and they figure the possible designations of universalities and the equal possible world circulation of the novel.

\section{Contemporary International/World Detective/Investigation Novel, Bildungsroman and Historical Novel: Partial Connections and Imminent, Immanent and Commensurate Worlds - In Search of Klingsor, Kafka on the Shore, The Moor's Last Sigh}

Partial connections' specificities characterize also, as we have remarked, contemporary well-defined kinds of novels - detective/investigation novel, Bildungsroman, and historical novel - that use international or world themes and are widely circulated. The critical Western tradition that was established in the $19^{\text {th }}$ century defines these kinds of novels as relying upon the reduction of their narratives, characters, worlds and time-lines to mono-causal data; the same reduction applies to the world that each evokes. Due to these reductions, each kind is antinomian: detective/investigation novel: one single truth is opposed to many possible truths; Bildungsroman: the adaptive approach to one world excludes the recognition of other worlds; historical novel: history is incommensurate to any individual and group that however recognize it as determinant. The counterpart of these novels is often defined as "exomimetic", 
BESSIÈRE

i.e. describing a world that is total, complete, causal and unique, but discordant with our own whole world. Reversely, to ally these kinds of novels with international or world themes and "partial connections" make them the novels of many contextual worlds and our whole world, that are equal. Due to their international or world themes and their partial connections, they dismantle their constitutive antinomies. This dismantling is the main condition to have these kinds of novels widely circulated and viewed as world works, with no systematic representation of our whole world and no restriction of their worlds to one local world. By altering and inversing their constitutive logic, these kinds of novels show the conditions that command the writing of what we have just called evocations of analogical realities and truths, and analogical fictions - i.e. novels' images and representations empower their transmissibility and universalization. The novels of one world become the novels of global differences.

Detective/investigation novel, "partial connections”, world images and imminence - Jorge Volpi's In Search of Klingsor. The detective/investigation novel - in principle - perfectly demonstrates the reduction of possible worlds to a single one that should include a total chain of causes. This reduction of wide worlds to causal chains should be deemed contradictory: the complete world of the detective/investigation novel is selective; it demonstrates that many relations are useless for what regards the investigation, and prevents us from viewing our world as the field of many analogical realities and truths. This contradiction can be rephrased as follows: even though the action that triggers the investigation is surprising and questioning, this kind of novel, because it is conclusive, prevents us from recognizing any imminence in our world and from figuring any attention to what comes next. To restore this sense of imminence and these analogies equates with rising with the occasion of what is coming, designating our world's broader scope, and qualifying the action that is investigated as incommensurate with any of its characterizations causal chains should be viewed only as some of the many relations to be associated with the investigated action. Jorge Volpi's In Search of Klingsor, an international/world novel, deconstructs the antinomies of the detectiveinvestigation novel, and by substituting partial connections to causal chains, it exemplifies this restoration, and constructs analogical truths and realities that are in accordance with our wide world - the one of the 1939-1945 war, a world war. Let us identify the paradoxes that motivate the use of partial connections and make this restoration possible. The novel is explicitly defined as a fictional/false construct: its postface provides a large bibliography of books and biographies about the European physicists who established the basis for 
nuclear research - i.e. the documentation upon which the novel relies - and emphasizes that Klingsor, the character who, in the novel, is supposed to have directed the whole Nazi nuclear research and remains with no clear identification, had no real existence. The investigation that is developed is a fantasy, though it refers to many historical data. Consequently, In Search of Klingsor imposes a question: why should we evoke the scientific background of World War II under the guise of an inconclusive (and fake) investigation? The answer is: all the relations that the investigation delineates are, due to their inconclusiveness, partial connections. The latter enable us to identify the contacts between scientists and between Allied authorities and German people in many extended and eventually contradictory ways, and to describe all the novel's characters according to many mutual implications and many kinds of references and orders. The investigation does not restrict the relations it delineates to a causal chain, but expands and views them as designating these physicists' various worlds and their whole world context, World War II. This description of the broader context is possible only through these worlds and their analogical identifications that the novel's partial connections authorize. The fake investigation fulfills a double function. On the one hand, it constructs analogical realities and fictions that are the only means to designate World War II's incommensurate reality and to reflect the latter in daily scenes, whose scopes are narrow and inadequate. On the other hand, due to their inconclusiveness and their metonymical partiality, and to their association with an inexistent character who should embody the whole military research power and scientific community and more broadly the whole human world, all these fictional searches embody the imminence of what might come, and, due their sequence, demonstrate that this imminence is constant. The imminence of what might come cannot be separated from the image of the whole world, the container of all possibilities and futures, and the support for literary representations of analogical realities and truths: due to the inconclusive investigation, these representations are metonymic and partially connected, and thereby bases for world fictions. That is why In Search of Klingsor is circulated world-wide and read.

Bildungsroman, "partial connections" and the gift of whole world's plurality - Haruki Murakami's Kafka on the Shore. Let us ask our initial question: why Haruki Murakami's Japanese Bildungsroman, Kafka on the Shore, with few references to foreign cultures and no explicit world codes, has been be widely translated, circulated, and qualified as a world novel, a universalized narrative? The answer requests a short clarification about the Bildungsroman. The latter is paradoxical and antinomian, like the detective/investigation 
BESSIÈRE

novel. It shows a wide array of cultural and ethical symbols that, in a society, identify and organize the local realities, codes and values, on the one hand; on the other hand, it focuses upon the recognition and practice of only some of these symbols by the characters involved in the apprenticeship of these realities, codes, and values. This constitutive antinomy has been interpreted in Western literatures in many ways that run from any narrative's foundational tension between classification and change to modern societies' failure to efficiently hierarchize and legitimize their values and rules. Actually, this antinomy should be read in a way that reverses the interpretations we have just quoted. The alliance of classification and apprenticeship (i.e. changes that are referred to characters) in the Bildungsroman is only a specification of a more simple (and consequently more important) duality: any approach to any world and our world unites predicating (nominations and attributions of predicates) data (agents, actions, objects, realities), inventorying (series of predications are established), and empowering the sequences of predications to interplay: because they are synonymous with series of times, predications are distinct and continuous, overlap and designate changes. Their series are equivalents to partial connections. In other words, the antinomy that our critical Western tradition identifies in the Bildungsroman characterizes a discourse - nomination and change, and consequently partial connections that we can have about our world. This whole world is implied in this kind of discourse because our series of predications and partial connections are, by definition, infinite and, even though we can say nothing about our world in itself, this world is for us all that we can say about it and consequently a whole always ready to be predicated.

Due to its discourse that is exemplarily predication, inventory and interplay of predications, the international/world Bildungsroman is, per se, universally relevant. It demonstrates this relevance with no alteration and no general identification of the society's realities, codes and values it evokes, because it enables a double reading: reading of the localized apprenticeship, on the one hand, and, on the other hand, of the broad interplay of predications, series of predications and sequences of time - of partial connections. Haruki Murakami's Kafka on the Shore authorizes this double reading. We can view Kafka Tamura's experiences as the accomplishment of his father's prophecy - you will kill your father and sleep with your mother - and the apprenticeship of religious and spiritual Japanese beliefs. We can read the same experiences with no confirmation of this accomplishment and of this apprenticeship because the narrative segments that refer to them are inconclusive, often overlap, present or function as kinds of mutual comments, i.e. partial connections. Whatever 
reading we apply, the novel first appears as one universe of discourse, with many conjunctions and concatenations. The fact that many of the latter are not ascertainable indicates that the narrative is a means of conjunction treated as all-inclusive. All-inclusiveness - the best way to represent the world that is one is heterogeneous: it shows various domains of agents, actions and objects within one domain, these agents, actions and objects are connected - that are linked because they share these agents, actions and objects, whose predications change according to the domain to which they are referred. Depending on the domains he is referred to, Kafka Tamura is defined and acts differently, even though his nominal identity does not change. There is no explicit conclusion to any narrative segment because no domain or no part of this one universe of discourse is excluded - many agents, actions and objects are referred to many domains and figure partial connections. Japanese locations and cultural references do not restrict this all-inclusiveness because they are first defined by the specificities and interplay of this one universe's domains. Kafka on the Shore's world-wide transmissibility relies upon its all-inclusiveness and interplay of domains, and on the presentation of a world completely offered with no restriction of its potentialities, that are immanent to all its evocations and ready to be recognized by anyone, with no compliance with any kind of paradigm, even though the latter refers to Japan.

\section{International/World Historical Novel and history that is commen- surate with human subjects - Salman Rushdie's The Moor's Last Sigh.} According to Fredric Jameson, in our world, due to globalization and the flattening of all actions and values, "the historical novel seems doomed to make arbitrary selections from the great menu of the past, so many differing and colorful segments or periods catering to the historicist taste, and all now, in full globalization, more or less equal in value. [...] How to have confidence in the presence and stability of any of the allegedly world-historical figures of the past when we have lost our own?” (Jameson 2013: 691) We do not intend to comment upon Jameson's opinion. For the sake of our argument, let us just highlight that the implicit assertion of these lines is triple. 1. Our world's time is the finite time of the finite world of globalization. 2. Because this world is finite, it makes historical and present references equal, and does not allow to hierarchize agents and actions whatever their impacts are. 3. Because the recognition of past events and their links to the present time equates with fetishization, i.e. the singularization of events, actions, agents, groups, that are consequently hyperbolized, history and globalization prevent from practicing any kind of hermeneutics of (historical) situations - any historical context could finally be viewed as the disparate sum of its agents, actions and objects. 
BESSIÈRE

The historical novel - at least, its contemporary examples - is antinomian because its temporality prioritizes the present of the narrative situation and refers other temporalities to it.

Responses to these limits should demonstrate that our finite world is paradoxically infinite and can show time strata, that any singularization identifies more than who or what is singularized, and finally that any historical scene - even though it cannot be inserted into a clear causal sequence designates wider contexts and their interconnections. None of these responses forbids us to comply with our contemporary cultural paradigms for what regards time and history: we can offer a flat view of the latter - equivalences of many moments and places -, emphasize the undecidability that results, and recognize that in the postmodern, everything and any reference to the past are images, and that history may appear as a "temporal span" that exceeds "the biological limits of the individual human organism" (Jameson 213: 794) i.e. history contradicts existential limits. In other words, the contemporary impossibility of the historical novel can be turned into its possibility, and, due to this reversion, this kind of novel can contribute to asserting the sense of history, that is to say: to restore the commensurable view human agents can have of long sequences of past events. This assertion does not imply an ideological view. It suggests that historical segments can designate the concordance of past and present times and of their abundant signs, that our contemporary finite (globalized) world can be connected to many past contexts, and wide relations apply to any time and any space. Singularization and fetishization should no longer be deemed a falsification of history, but what enables to focus upon specific links between times, places and agents. By using partial connections, Rushdie's The Moor's Last Sigh, an international/ world novel, responds to the historical novel's impossibility that is pointed to by Jameson, and characterizes the universality of the historical novel, whatever history and past are referred to - although Rushdie's novel could be first read as exemplifying the prioritization of the present.

Partial connections are obvious between the last Moorish king of Grenada, contemporary India and its many identifications, the novel's main characters, the narrator's life and narration, his mother's paintings, other images and plot's intricacies. On the one hand, these partial connections set up cross-temporal and cross-spatial compatibilities and comparisons between the novel's data and designate the possible rhetorical "loci" to which any character can be referred, and which any reader can use to "partially" identify the necessity of the novel's fable. On the other hand, these partial connections prevent us from reading a strict continuity and coherence between the past and the present, the historical 
data and the many novel's disjunctions. Frequent historical parallelisms and palimpsests confirm that any literal coherence is just partial. The partial connections and the inseparable presentations of the history of a family and of the history of India define the reflexive and hermeneutic stand of the novel, that is made obvious from the beginning of the narration: the overall novel's fable is to be identified either with the intricate plot or with the many "bunches of scribbled sheets, swings of the hammer, sharp exclamations of two-inch nails" (Rushdie 1996: 15). The novel itself is a kind of partial connection.

These "partial connections" rely upon constant bifurcations between two figurations of the whole that the history of the narrator's family should constitute. On the one hand, wholeness seems the result of the sum of its parts and on the other hand, many details seem to summon wholeness. These bifurcations depend on the narrator's uses of the various framings that apply to the same data: his family tree is to be read either as a continuity and a sum or as inviting through each person it quotes to the designation of a specific totality. His mother Aurora's paintings are to be viewed either as pointing to her closed world and its internal broader perspectives or as designating wider relations. No internal or external limits can be ascribed to these extensions of partial connections and to the scale variations that they cause. The "whole thing", which the novel and India should be, does not seem to fall into place. That founds the stop and search attitude of the narrator (and of readers as well).

The "partiality" and uncertain limits of these connections make a paradox: they characterize history at once as relatable and as exceeding the life of Moraes Zogoiby even though the latter presents his family tree and narrates the actions of many of his ancestors. If history and ancestors' biographies are excesses and incommensurate with their narrator, on the one hand, and, on the other hand, the latter goes on with narrating his life and family tree, some specific hermeneutics is implied. The narrator practices a kind of adaptive interpretation of his life and of the past. He embeds world images from this past onto his present and can identify historical time-lines that are beyond his scope as familiar. Because they are described according to partial connections, they authorize a reverse move: the embedding of the present into the past. This double embedding makes historical broad images and sequences commensurate with any individual's past and present, and, contrarily to Jameson's remarks, it restores historical novels' relevance. Due to our finite world, no agent, no action, no group, no place can easily recognize the infinite of history, and all consequently call for more links - that defines the paradox of finitude and legitimizes the right and duty not to abandon allegorizing any past and the present. The Last Moor's Sigh and its partial connections 
BESSIÈRE

respond to this paradox and restore a relational sense of history, with no recognition of any ideological view, no systematic interpretation of history, no explicit identification of causal chains. This restoration performs more than the imaginative recognition of these timelines and spaces; its interplay of discontinuity and continuity, the chains of partial connections - especially the one that opens and closes the narrative - evoke, through many negative descriptions of the present and the past, a desire for the global recognition of history's commensurability. This desire defines the novel's general relevance and transmissibility.

\section{Poetics of "Partial Connections" and Hermeneutic of Situation}

These international/world novels show narrators who strive to be situated Moraes Zogoiby in The Moor's Last Sigh, Gustav Links in In Search of Klingsor, Kafka Tamura in Kafka on the Shore -, while Tout-monde and its "tout-monde" should be defined as inextricable (Ménil 2014: 86). This difficulty to define situations and this inextricability result from the "enfolding world" and its "paradoxical unions", and the partial connections associated with them. Any place, any moment, and consequently any knowledge of this world seems to be embedded in relations and each carries its specificity and becomes one more nexus of relations. To tell stories and refer to history does not make an important change in how these narrators perceive their situations. By one more twist, the sense of narrative that each of these narrators exemplifies just adds to the dissipated images of this world and its local worlds, and makes of the world a wide constellation of times and places. This strife that all the narrators share confirms the absence of reference to any meta-culture, overall paradigm or general view of the novel. It has a major consequence: these narrators are committed to some kind of specific hermeneutics, that we suggest to call hermeneutics of situation and that defines also readers' responses to these novels.

These narrators demonstrate that to experience the world according to historical, social, cultural and symbolic dimensions discloses different scales of this world, and results in narratives that show no kind of conclusion. Toutmonde: abundant descriptions of historical and cultural differences and hybridity (a kind of stable alliance of identities) are of no avail to produce stable descriptions of this world. In Search of Klingsor: no documented and truthful narrative of world events and actions can produce a sense of global collectivity. Kafka on the Shore: no cultural, social, religious national - and international collective identifications can be deemed manifestly meaningful. The Moor's 
Last Sigh: no cultural, linguistic, national, political identities can be viewed as parts of a manifest totality. No narrative teleology implies that no beginning should be determinant even though it opens a series of actions and events. Consequently, references to the past define it as explicitly non-determinant, even though history is not negated and explicit factual historical data are referred to. The latter finally take a minor form (biographical identifications of many persons who are evoked) in Tout-monde, and, though they are obvious and documented in In Search of Klingsor, non-ambiguous in Kafka on the Shore, and constant in The Moor's Last Sigh, they cannot be disassociated from many fantasies.

These characteristics of the novels are counterparts of what makes their transmissibility and power universalized. They are inseparable from these novels' specific poetics. Due to partial connections, no narrative shows either a constitutive enigma - in In the Search of Klingsor, the mystery of Klingsor is declared a fictional construct -, or a determining structure, or a clear continuity - the latter is always to be inferred and checked through the chains of overlapping partial connections and the palimpsests they delineate. Because any agent or any object is linked to several kinds of orders, continuous as the process of narration might seem, the more faithfully the narrator narrates and describes, the more obvious are the internal discontinuities of orders, actions - narration is a surface understanding which conceals gaps and bumps... Novels' narrators make the act of narrating the reflexive deployment of partial connections. The descriptions of places and scenes are mostly limited to representing the locations of partial connections. Scenes and actions may be deemed unrealistic - realism and counter-realism are not an issue since the only salient features to be actualized are those of partial connections.

Narrators' strive to define their responses to these international/world novels' asymmetry that their views of the world and of history and their poetics construct. On the one hand, partial connections and the narratives, representations, time-lines they command offer a specific description of our wide world to be identified in Tout-monde and In Search of Klingsor, and inferred in Kafka on the Shore and The Moor's Last Sigh: this world is one single world, whose unicity, unity, and totality are coordinated with many-ness and imply imminence, immanence and the commensurability of history with human subjects. On the other hand, this description breaks the image of a global society or world and makes any grand narrative useless useless. In Tout-monde, to this image and this kind of narrative, a view of our unframed world, Glissant's "tout-monde", is substituted. Japan in Kafka on the shore, India in The Last Moor's Sigh and World War II In Search of Klingsor are finally shown unframed: Japan's great 
BESSIÈRE

symbols are reduced to a short parenthesis in the life of a teenager; India's history is emblematized by Moraes Zogoiby's story of his "fall from grace" (Rushdie 1996: 18); and World War II can be retold under the guise of a fake enigma. The possible congruence of the novels' coordination of unicity and many-ness with the unframing of our world is made possible by the reversion of the antinomies of the investigation novel, the Bildungsroman and the historical novel: any representation of history and any world can concatenate agents and actions, events and places, and therefore figures many possible experiences, and is ready to be universalized.

Readers' recognition of this congruence supposes they practice symptomatic readings, i.e. readings that are not mono-causal or reifying, and that do not lead to the conclusion that widely circulated novels are linked to something unsayable. Rather, readers should hold a specific position: they are not only submitted to the subjective stand, which symptomatic readings impose; they are also "relocated", i.e. situated according to the cognitive, cultural and ethical implications, which are attached to novels' symptoms, and according to their own world consciousness. The latter is doubly characterized: due to the perception of the asymmetry of the novels, readers are prevented from referring to any single narrative, world view and from synthetizing novels' data, on the one hand; on the other hand, because they do not negate that they are living in one world - our world - and that this unicity makes it possible to designate many connections and hierarchies between novels' worlds and our world, they view the novels' unframed world as some kind of unified universe.

Because of this reading, readers should become flexible in identifying historically, presently, locally, globally and aesthetically significant segments and scenes in the novels, and develop some hermeneutics of situation: whatever their cultural identities are, they tend to perceive the novels as mirroring the temporal and spatial connectivity and universalization of any existential moment. This practice of hermeneutics of situation makes it possible to actualize the relevance of the widely circulated and/or international novels, and to bypass the asymmetry of literary poetics and the missing designation of any meta-culture. From this specific hermeneutic angle, Glissant's title, Toutmonde, should be reinterpreted: it first designates the global world - to which black people are linked and which they constantly represent, so proving their universal emancipation -; it also means, as the French expression allows to read, "n'importe quel monde" ("any world"), that is to say, any world, with no kind of exclusion - literally any world, and any people. Although any reading is singular, readers exemplify the universal or general audience that studies in rhetoric define, and novels' universalities and universalization are viewed as 
pointing to the totality of the world and its inclusiveness, with no designation of any paradigm. The practice of hermeneutics of situation offers a response to the totalization-detotalization duality.

This specific status of contemporary international/world novels, the specific view of the world they imply - a world of paradoxical unions and an enfolding universe -, their literary and cultural compositions (partial connections) and the kind of reading they trigger (hermeneutics of situation) should invite us to revise many tenets of contemporary studies in World Literature - the notions of "world space of literature" and "triangulation reading" are paradoxical: critical abstractions that should account for the universalization of contemporary literary works; they do not take into account the implications of critical references to the word "World".

Let us define the arguments that this article offers as contributing to a critical exercise that moves from practice - the reading of novels, which is commended by the status of the latter - to suggestions that address theoretical issues in the universalization of literatures, with a discrete designation of a genealogy of references to the world - William James -, that is forgotten but essential.

\section{Coda - Definitions of the Three Types of Narratives and of Analogical Realities, Truths and Fictions}

Narratives of the imminent: the truths we recognize in world history should be neither contested, nor read as a repertoire of responses to be re-echoed by world novels. Should these novels show the manifest lack of unity principle in any narrative, and should they work by taking some fragments of the world, they should be able to restore the sense of the event, of the imminent, and become kinds of and proofs of events and of the imminent as they circulate, whatever kind of unicity or unity is recognized to our world.

Narratives of the immanent: whatever cultural symbols are available and whatever wholes they designate, they are always limited exemplifications of the immanent world, which request many narratives to be evoked. Immanence is to be equated with plurality, and is made obvious because no totalizing symbol or narrative can account for the immanent.

Narratives of the commensurability of history with human subjects: The Moor's Last Sigh is a paradoxical novel - it demonstrates how its narrator got lost in history, the broad history of two continents -, but this demonstration implies that history can be told according the destiny of an individual - in other 
BESSIÈRE

words, there is no kind of absolute view of history and the world, both give the word to the individual and the imminence that he/she designates in his/her own experience of history.

Analogical realities, analogical truths, analogical fictions. Segments of a narrative are to be qualified as homonymous for what regards their relation to truth - they all evoke the same wide context in a novel. This relation is analogical because these fictions only expose and discuss a set of facts about this context. Fictions' homonymy and analogical truths found the cohesion of the sequences of partial connections, and characterize any reference to any action, agent, place and scene as acceptable. To decide about the real or the unreal of these fictions is not consequently an issue. Their homonymy and analogical truths make all narrative segments of the novels equally relevant, readable, and contribute to the novels' transmissibility and universalization.

\author{
Jean Bessière \\ jean.bessiere@sorbonne-nouvelle.fr \\ Université Sorbonne Nouvelle - Paris 3, FRANCE \\ c/o Interlitteraria \\ Ülikooli 16-113 \\ 51003 Tartu \\ EESTI / ESTONIA
}

\title{
Bibliography
}

Bauman, Z. 2001. Culture as Praxis. London: Sage Publications.

Glissant, E. 1995. Tout-monde. Paris: Gallimard-Folio. [First ed. 1993.]

James, W. 1921. Pragmatism: a New Name for Old Ways of Thinking. Popular Lectures on Philosophy. New York: Longmans, Green and Co.

Jameson, F. 2013. The Antinomies of Realism. London: Verso. [References to e-pub edition.]

Kapferer, B. 2011. Strathern's New Comparative Anthropology: Thoughts from Hagen and Zambia. - Common Knowledge, 17: 1, 104-110.

Ménil, A. 2014. Les offrandes d'Edouard Glissant: de la créolisation au tout-monde. Littérature, 174, 73-87.

Murakami, H. 2006. Kafka on the Shore. New York: Vintage International. [Transl. by Ph. Gabriel.]

Osborne, P. 1995. The Politics of Time: Modernity and Avant-garde. London: Verso.

Rushdie, S. 1996. The Moor's Last Sigh. Toronto: Vintage Canada Edition. [References to e-pub edtion.] 
Contemporary International/World Novels' Transmissibility

Strathern, M. 2004. Partial Connections. Updated Edition. Walnut Creek, CA: Altmaria Press.

Volpi, J. 2003. In Search of Klingsor. London: Harper Collins Publishers. [Transl. by K. Cordero.] 